\title{
Comparison of Two Diffusers in a Transonic Centrifugal Compressor
}

\author{
Koji Nakagawa \\ Department of Mechanical Engineering, Hakodate National College of Technology, Hakodate, \\ Hokkaido, Japan
}

\author{
Hiroshi Hayami \\ Institute of Advanced Material Study, Kyushu University, Kasuga, Fukuoka, Japan \\ Yuichi Keimi \\ Refrigerating-Heating Division, Hitachi Industries Co., Ltd., Tsuchiura, Ibaraki, Japan
}

Flow mechanisms suppressing the flow separation in two diffusers, a low-solidity cascade diffuser and a vaned diffuser with additional small vanes near the inlet, were compared mainly by numerical simulation. As the superiority of the low-solidity cascade diffuser was expected, a series of experiments was conducted using a transonic centrifugal compressor with a maximum pressure ratio of 7 . The performance of the compressor with the vaned diffuser was comparable to that of the low-solidity cascade diffuser only between the surge point and the design flow rate at a pressure ratio of 3.5. The maximum flow rate of the vaned diffuser was lower than that of the low-solidity cascade diffuser. At higher rotational speeds, the pressure ratio at the surge point, the efficiency, and the flow range of the low-solidity cascade diffuser exceded those of a vaned diffuser at a pressure ratio of 3.5.

Keywords Compressor, Diffuser, Numerical analysis, Stall

In many radial compressors, vaned diffusers are widely used to obtain high efficiency. However, this causes the problem of a

Received 25 June 2002; accepted 1 July 2002.

The authors thank Toshiyuki Sato of the Research \& Development Laboratory of Hitachi Industries Co., Ltd., for the execution of the numerical simulations. The authors are also grateful to Hideo Sasaki and Hidenori Hasegawa, who were graduate students while this paper was being composed, and Nobumasa Kawaguchi of Kyushu University who assisted in running the experiments.

Address correspondence to Koji Nakagawa, Department of Mechanical Engineering, Hakodate National College of Technology, 14-1 Tokura-cho, Hokkaido, 042-8501, Japan. E-mail: nakagako@ hakodate-ct.ac.jp narrow flow range. A low-solidity circular cascade diffuser was proposed so as to avoid this problem in regions of subsonic flow (Senoo et al., 1983) and transonic flow (Hayami et al., 1990). The special feature is that this type of diffuser does not have a throat.

Diffusers with throats, such as channel-type diffusers, are still in wide use, despite the problem of choking, because of the accumulation of data concerning them. To extend the flow range of these diffusers, modification of the vane shape is practical because of its simplicity. The V-shaped inlet (Dallenbach and Van Le, 1960) and the pipe diffuser (Morris and Kenny, 1971) are representative techniques. This $\mathrm{V}$ shape was effective even in subsonic cases (Yoshinaga et al., 1980). The three-dimensionally twisted vane (Jansen and Rautenberg, 1982) extended the available operation range by a factor of 2 . A common feature of these diffusers is that the vane inlet matches the real flow. As a flow distortion is stronger on the shroud side than on the hub side, small vanes were added near the diffuser's vane inlet on the shroud side. This diffuser had a remarkable effect in a highsubsonic, centrifugal compressor with a pressure ratio of 2 , with a suction damper (Nakagawa et al., 1995). When the damper opening was $40 \%$, the surge flow rate decreased by $35 \%$ and the maximum head rise increased by $15 \%$. At full damper opening, the flow range and the maximum head rise increased only a little. In addition, a rotating stall occurred just near the surge flow rate at both damper openings. These results suggested that the added small vanes did not fully suppress a flow separation in the diffuser channel.

In the first half of this article, the flow mechanisms suppressing the flow separation of two diffusers, a low-solidity cascade diffuser (called an SVD in this paper, for simplicity) and a vaned diffuser with small vane added near the vane inlet (called a VDA), were compared in experiments using a high subsonic 

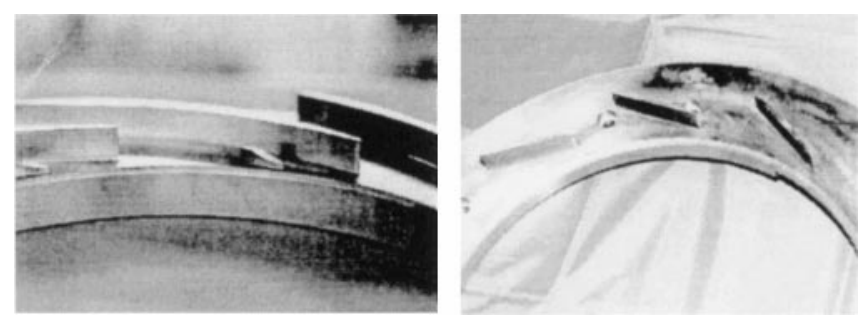

FIGURE 1

View of tested diffusers (a) Vaned diffuser with small vanes added near the diffuser vane inlet (VDA). (b) Low-solidity cascade diffuser (SVD).

compressor and mainly by numerical simulation. The stronger separation-suppressing effect in the SVD was expected to cause a wider flow range in the transonic centrifugal compressor in which diffuser stall restricts the lower limit of the flow range. To prove this point, a series of experiments were conducted using a transonic centrifugal compressor.

\section{FLOW MECHANISM OF SUPPRESSING SEPARATION}

Figure 1 shows the VDA and the SVD used in a high subsonic centrifugal compressor with a pressure ratio 2 (Nakagawa et al., 1995). Table 1 shows the main specifications. The basic parameters of the SVD are similar to those of an SVD69 in the literature (Hayami et al., 1990). To avoid confusion between the main vane and the small vane, the terms blade or main blade are used to refer to the main vane in this article. The blade's number is 11 , the solidity is 0.69 , and the leading-edge position is located at 1.1 times the radius of impeller exit. The blade profile was based on an NACA66 series. The difference between the SVD and the SVD69 is the blade profile. Figure 2 shows a cross-section of the test compressor. The diameter of the impeller was $328 \mathrm{~mm}$ and the blade's backward sweep angle was 50 degrees at the exit. The impeller exit width was $23 \mathrm{~mm}$. The diffuser height was $23 \mathrm{~mm}$, too.

TABLE 1

Main Specifications of Tested Diffusers

\begin{tabular}{|c|c|c|c|c|}
\hline Diffuser & VDA & VDAT & SVD & SVDT \\
\hline$Z$ & 18 & 11 & 11 & \\
\hline$r_{3 \mathrm{e}} / r_{3 \mathrm{i}}$ & 1.33 & 1.35 & 1.152 & \\
\hline$L / W_{3 \mathrm{i}}$ & 6.4 & 5.5 & 2.68 & \\
\hline $2 \theta$ (deg.) & 9.1 & 12.1 & 17.7 & \\
\hline$A_{3 \mathrm{e}} / A_{3 \mathrm{i}}$ & 2.01 & 2.18 & 1.83 & \\
\hline$b_{3} / D_{2}$ & 0.070 & 0.034 & 0.070 & 0.034 \\
\hline
\end{tabular}

VDA and SVD are designed for a high subsonic compressor. VDAT and SVDT are designed for a transonic compressor.

$A_{3 \mathrm{i}}=\pi D_{3 \mathrm{i}} b_{3 \mathrm{i}} \sin \left(\beta_{3 \mathrm{i}}\right)$

$A_{3 \mathrm{e}}=\pi D_{3 \mathrm{e}} b_{3 \mathrm{e}} \sin \left(\beta_{3 \mathrm{e}}\right)$

$W_{3 \mathrm{i}}=\pi D_{3 \mathrm{i}} \sin \left(\beta_{3 \mathrm{i}}\right) / Z$

$2 \theta=2 \tan ^{-1}\left\{\left(A_{3 \mathrm{e}}-A_{3 \mathrm{i}}\right) /\left(2 b_{3 \mathrm{i}} L Z\right)\right\}$

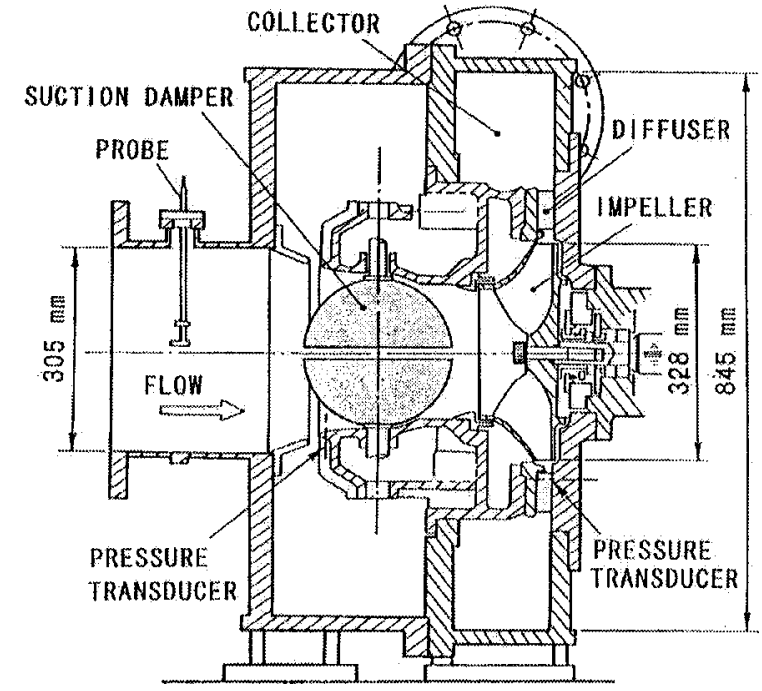

FIGURE 2

Cross-section of a compressor.

The rotational speed was $11,500 \mathrm{rpm}$. HCFC22 was used as a working gas and the pressure level was $0.04 \mathrm{MPa}$ at the inlet and $0.08 \mathrm{MPa}$ at the outlet. The inlet temperature was controlled between 273 and $277 \mathrm{~K}$. The Mach number of absolute velocity at the impeller's exit was 0.76 at the design flow rate.

Figure 3 shows the normalized characteristics of the compressor. The performance of the compressor stage was evaluated by using measured total pressures and total temperatures at the inlet and outlet. At 100\% damper opening, there was no difference in head rise and efficiency between the two types of diffusers. At $40 \%$ damper opening, on the other hand, the superiority of the SVD is clear, as was stated by Nakagawa and Uraki (1998). To investigate the flow distribution at the surge limit, static pressures were measured on the shroud sides of both diffusers.

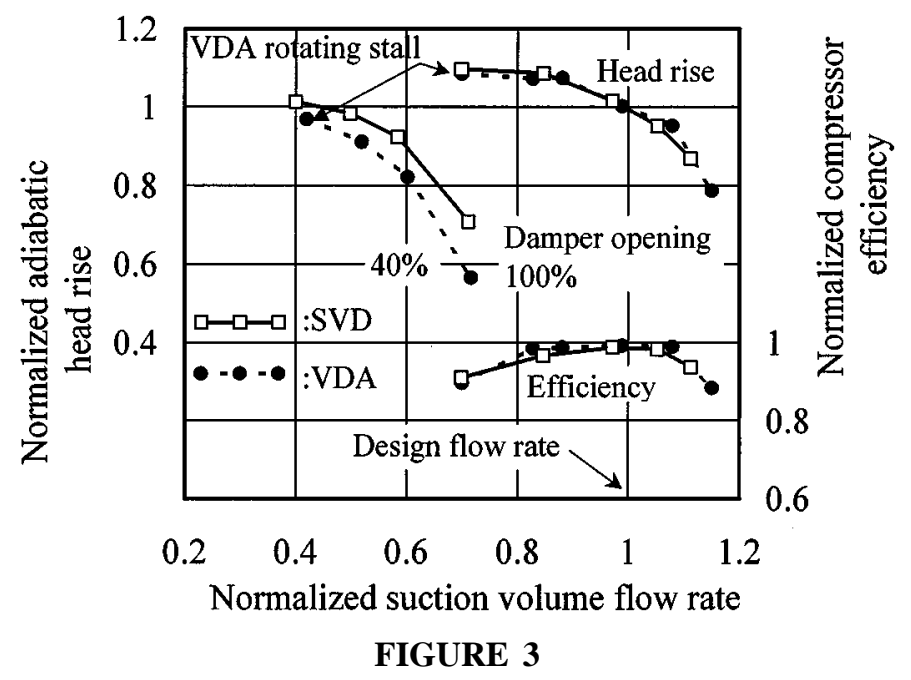

Compressor characteristics. 


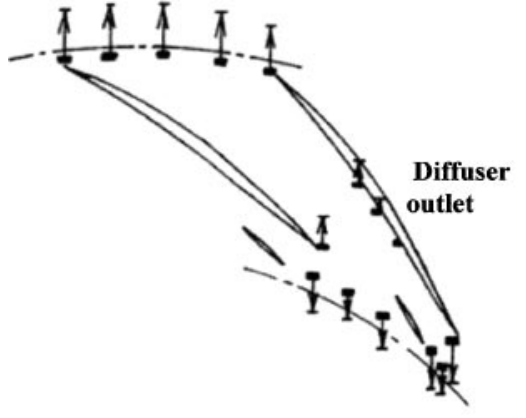

(a) VDA

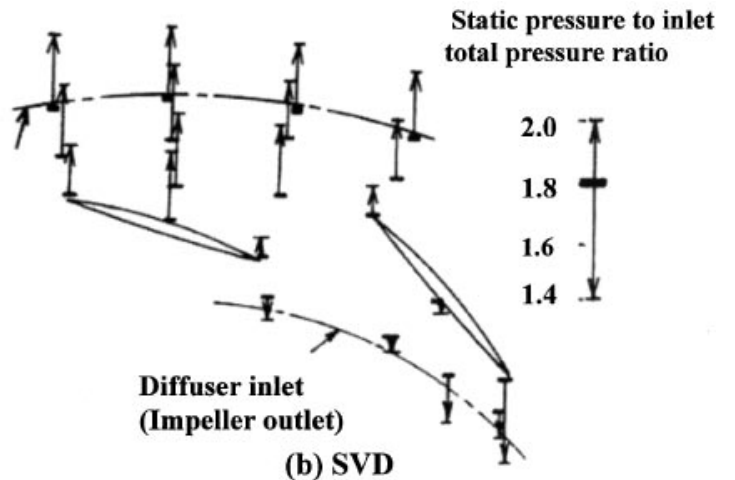

(b) SVD

FIGURE 4

Pressure distribution on shroud side (measured at $40 \%$ damper opening).

Figure 4 shows the normalized static pressure distribution at surge limit at a $40 \%$ damper opening. For simplicity, the difference from the value 1.8 is shown by the arrowhead and the length of the rod. The pressure at the throat is higher than the pressure near the suction surface of the leading edge in the VDA. In the SVD, the pressure near the suction surface of the trailing edge is higher than the pressure near the suction surface of the leading edge. This suggests that the flow does not separate severely from the suction surface in either diffuser. It should be noted here that the flow in the SVD is more stable than the flow in the VDA.

To visualize the difference in flow pattern, numerical simulation was carried out. A code based on the finite volume element method and the k- $\varepsilon$ model for turbulent flow was used to simulate steady three-dimensional compressible flow. The number of volume elements was about 50,000 for one pitch of the diffuser channel. The boundary conditions are given at the diffuser inlet (impeller outlet) and at the diffuser outlet. The total pressure was assumed to be uniform at the diffuser inlet. The flow angle was assumed to be uniform circumferentially, but to be distributed spanwise at the diffuser inlet. Using measured values of the mass flow rate, the static pressures on the diffuser inlet wall, and the total temperature rise at the surge limit of the VDA at a $40 \%$ damper opening, and assuming an impeller blockage factor of $10 \%$, the total pressure and the mean flow angle were evaluated based on a one-dimensional calculation. This total pressure was used for the inlet boundary condition. Flow angle distribution was measured by a cobra type, three-hole Pitot tube in the vaneless diffuser in the compressor of Figure 2 (Nakagawa et al., 1995). As the area-averaged value of the measured flow angle distribution and the value obtained in the calculation of total pressure were not same, the measured flow angle was shifted to correct this discrepancy. Then these results were applied as the flow angle distribution at the inlet.

The simply averaged value of measured static pressure at the surge limit of the VDA at a $40 \%$ damper opening was used at the outer boundary condition. Because of the assumed blockage factor and the difference in radial position between static pressure taps and the impeller outlet, errors may exist at several points in the calculation. This amount of error is tolerable for the present qualitative visualization.

Figures 5 and 6 show the flow patterns in two diffusers. The flow rate was the value at the surge limit at a $40 \%$ damper opening when the VDA was used. The velocity patterns at $1 / 5$ the blade height from the shroud side (near the shroud side) are shown at a larger scale so as to clarify the suppression mechanism. The thick black arrows at the inlet in Figures 5(a) and 6(a) indicate the incoming flow direction. The direction near the shroud side is more tangential than that at midspan and near the hub side.

\section{VDA}

The measured pressure distribution, Figure 4(a), and the simulated one, Figure 5(b), have several common points, so we proceeded on the basis of the numerical simulation results. The common points are (1) the pressure change in the peripheral direction at the inlet is small; (2) the pressures at the pressure side and the suction side of the throat are nearly equal; (3) the pressure at the throat is higher than the pressure at the inlet; and (4) the pressure change in the peripheral direction at the exit is small. Because of the effect of the small vane, pressure patterns are different at $1 / 5$ and $4 / 5$ blade heights at the upstream of the throat. Downstream of the throat, pressure patterns are similar at those two blade heights. Although a small region of reverse flow can be seen, most fluids flow toward the exit at $4 / 5$ blade height. Near the shroud side ( $1 / 5$ blade height), the small vane guides the rapidly incoming fluids along the suction surface of main blade. This flow pushes the reverse flow from downstream so it does not move along the suction surface near the leading edge. As there exist several wide regions of reverse flow, on both the suction and the pressure surfaces, the flow is considered not to be fully stable. Then a rotating stall occurred in the experiments.

\section{SVD}

The measured pressure distribution, Figure 4(b), and the simulated one, Figure 6(b), have several common points, so we proceeded on the basis of the results of the numerical simulation. 


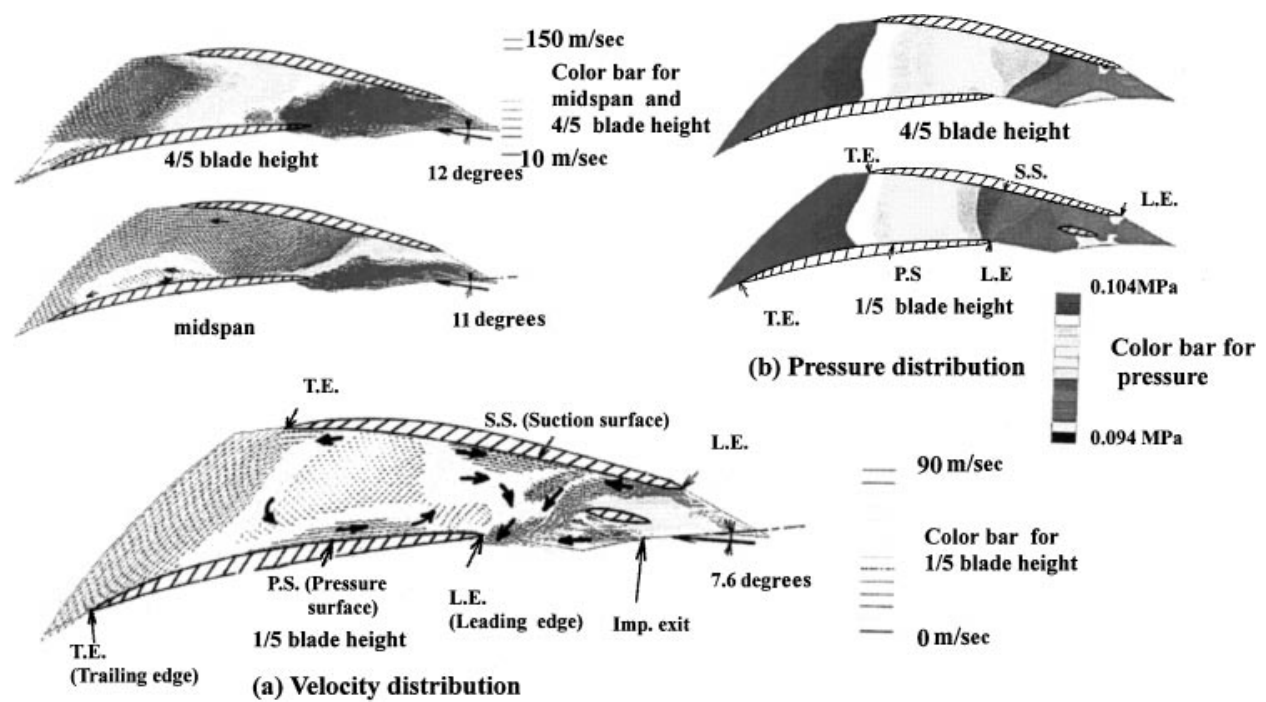

FIGURE 5

Results of numerical simulation (VDA).

The common points are (1) the pressure at the leading edge suction surface is lowest in the peripheral direction at the inlet, and (2) the pressure at the trailing edge suction surface is lowest in the peripheral distribution at the exit.

The pressure pattern difference is small at any blade height. There is no reverse flow on the suction surface. This is a distinct difference from the case of the VDA. Near the shroud side (1/5 blade height), fluids flow downstream along the suction surface, then turn to the pressure surface of the adjacent blade. Some of those fluids flow downstream along the pressure surface of the adjacent blade and the rest of the fluids flow into the adjacent channel (Senoo et al., 1983). As there exists no reverse flow along the vane surface, the flow should be more stable than in the VDA, and there was no clear rotating stall, even at the surge limit. The separation-suppressing effect of the SVD is expected to be stronger than that of the VDA.

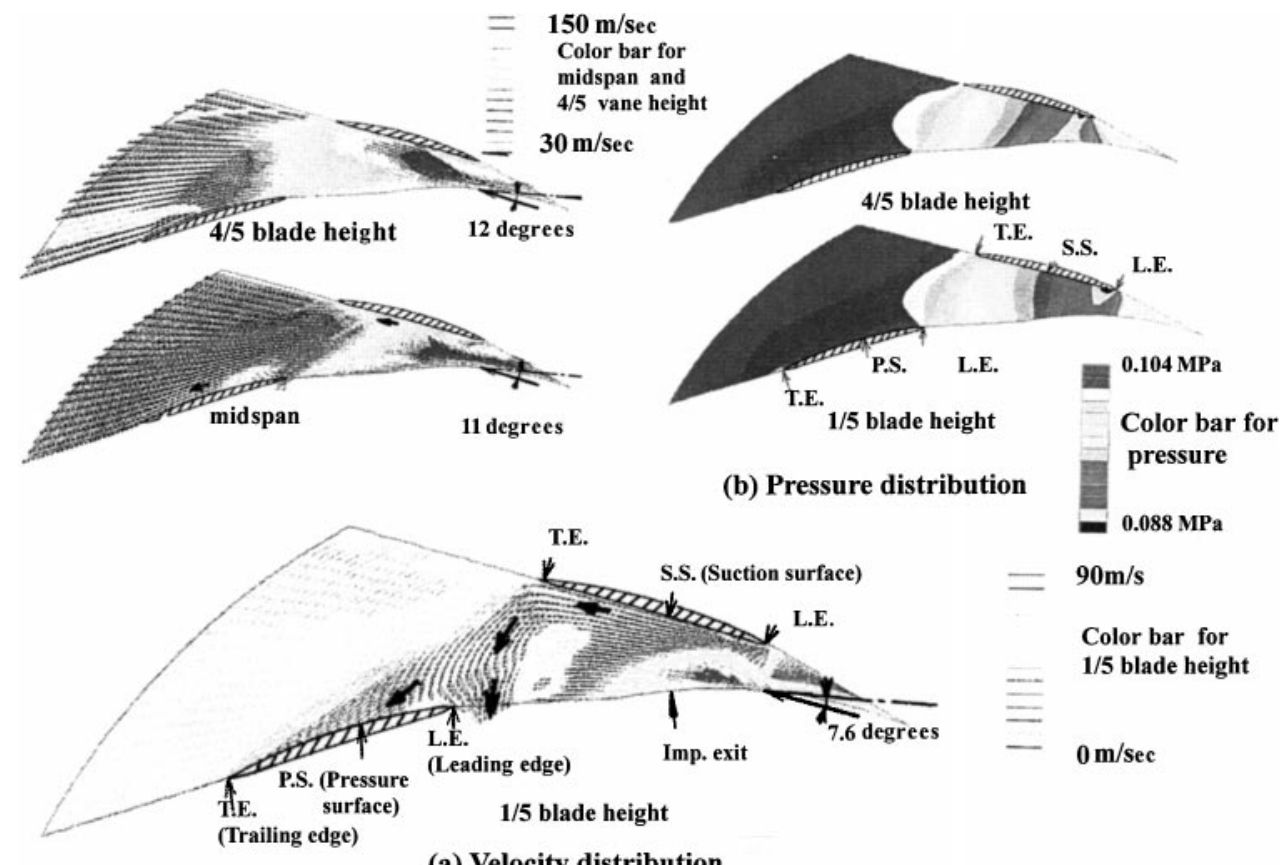

(a) Velocity distribution

FIGURE 6

Results of numerical simulation (SVD). 


\section{COMPARISON IN THE TRANSONIC CENTRIFUGAL COMPRESSOR}

To prove the superiority of the SVD to the VDA, a series of experiments was carried out using a transonic centrifugal compressor test rig, as described by Hayami and colleagues (1990). The diameter of the impeller was $280 \mathrm{~mm}$ and the blade's backward sweep angle was 40 degrees at the exit. The rotational speed was between 15,000 and $19,000 \mathrm{rpm}$. CFC12 was used as the working gas. The diffuser vane height was $9.4 \mathrm{~mm}$. To distinguish the diffusers used for the transonic centrifugal compressor from the diffusers used for the subsonic centrifugal compressor, " $T$ " is added at the end of SVD and VDA, that is SVDT and VDAT. A comparison of the specifications of the main vane is shown in Table 1. The specifications of the SVDT were similar to those of the SVD. The VDAT was newly designed to match the transonic centrifugal compressor at $M t=0.94$ and at a 3.5 pressure ratio. Most differences in parameters came from the vane number.

Figures 7 and 8 show a comparison of the stage performance. The ordinate in Figure 7 is the total pressure ratio $p_{4} / p_{0}$. The abscissa $G / G^{*}$ is the ratio of the mass flow rate to the choking flow rate in the suction pipe. The parameter $M t$ is the nominal Mach number of the inducer tip speed, which corresponds to the corrected speed.

For all operating points, the absolute flow Mach number exceeded unity at the impeller exit (Hayami et al., 1990). The surge flow rate of the VDAT was comparable only at $M t=0.94$ and $M t=1.041$. The choke flow rate of the SVDT was larger than that of the VDAT at $M t=0.94$. At higher $M t$, choke occurred in the impeller inducer and the difference in flow range depended on the stall limit of the diffuser. The pressure ratio of the SVDT at the surge point exceeded the value of the VDAT at all $M t$. This result showed that the SVDT works well even in the range in which the VDAT could not work.

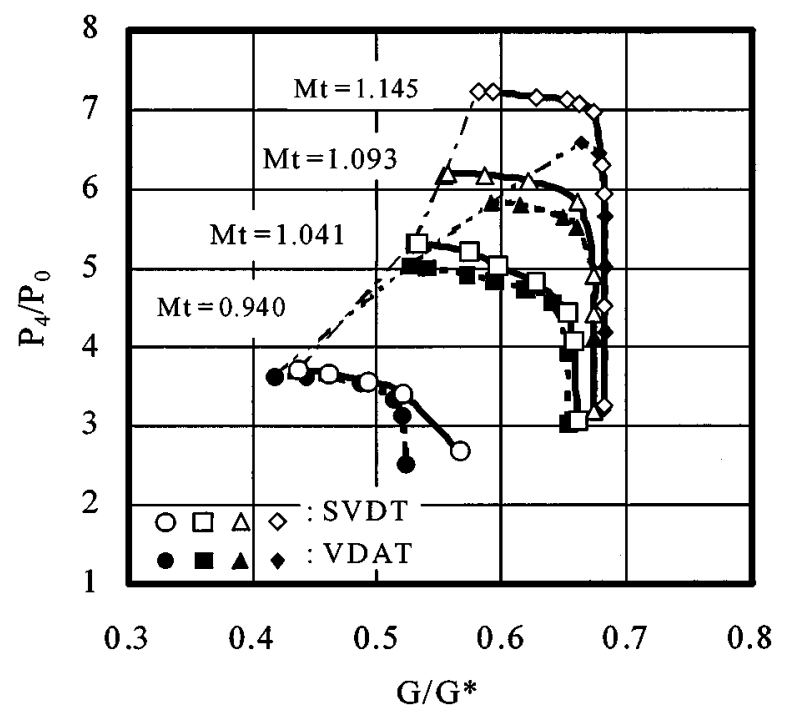

FIGURE 7

Comparison of pressure ratio.

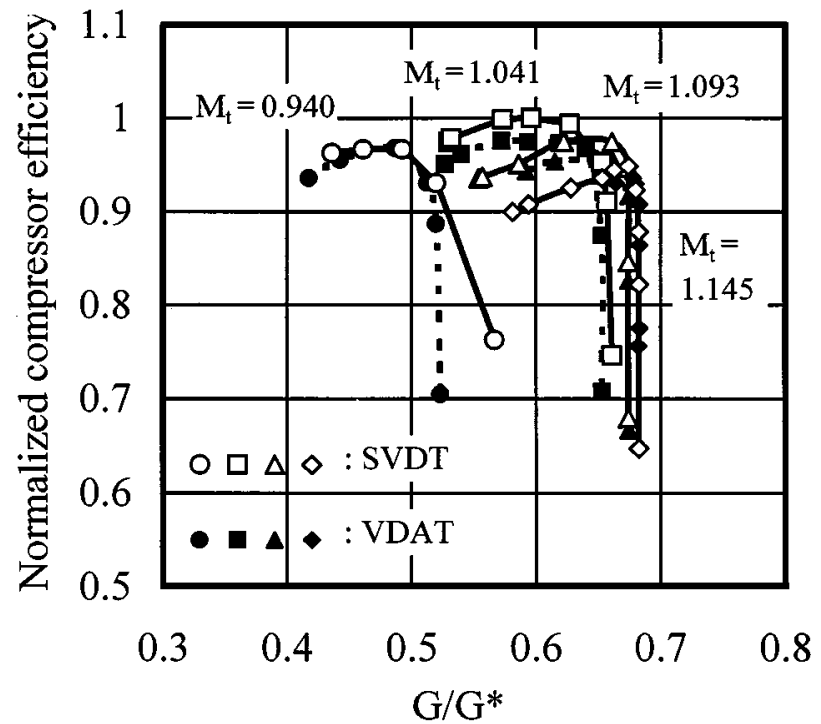

FIGURE 8

Comparison of efficiency.

Figure 8 shows a comparison of compressor efficiency. The efficiency is normalized by the peak value, which is almost the same in the case of the SVD69 (Hayami et al., 1990). The efficiency of the VDAT is comparable only at $M t=0.94$. At higher Mt, the VDAT could not realize good efficiency as the SVDT.

\section{CONCLUSIONS}

1. In the case of a high subsonic compressor, the SVD showed almost the same flow range, head, and efficiency as the VDA. At smaller damper openings and at the surge limit flow rate at any damper opening, the SVD was clearly better than the VDA.

2. The numerical simulation showed that near the shroud side of the VDA, the small vane guides the rapidly incoming flow along the suction surface of the main blade. These fluids push the reverse flow from downstream so they do not move along the suction surface near the leading edge. This is considered to be the flow mechanism suppressing a separation. As there exist several wide regions of reverse flow on both the suction and the pressure surfaces, the flow should be unstable.

3. In the case of the SVD, near the shroud side, fluids flow downstream along the suction surface, then turn toward the pressure surface of the adjacent blade. Some of those fluids flow downstream along the pressure surface of the adjacent blade and the rest of the fluids flow into the adjacent channel. As there exists no reverse flow along the vane surface, the flow should be more stable than that of the VDA. This is considered to be the cause of the stability of the SVD near the surge limit.

4. In the case of the transonic compressor, the SVDT exceeded the VDAT at higher pressure ratios. This superiority of the 
SVDT is considered to be a reflection of the flow mechanism suppressing separation in the diffuser.

\section{NOMENCLATURE}

A Cross-sectional area

$b$ Height of channel

$D$ Diameter

$G \quad$ Mass flow rate

$G^{*} \quad$ Choking mass flow rate in suction pipe

Mt Inducer tip Mach number

$L \quad$ Vane chord length

$P \quad$ Stagnation pressure

$r \quad$ Radius

$W \quad$ Equivalent width of channel

$Z \quad$ Vane number

$\beta \quad$ Vane angle measured from tangential direction

$2 \theta$ Diffuser divergence angle

\section{Subscripts}

0 Compressor inlet

2 Impeller exit

3i Diffuser cascade inlet

3e Diffuser cascade exit

4 Compressor exit

\section{REFERENCES}

Dallenbach, F., and Van Le, N. 1960. Supersonic diffuser for radial and mixed flow compressors. ASME Journal of Basic Engineering 82:973-979.

Hayami, H., Senoo, Y., and Utsunomiya, K. 1990. Application of lowsolidity cascade diffuser to transonic centrifugal compressor. ASME Journal of Turbomachinery 112:25-29.

Jansen, M., and Rautenberg, M. 1982. Design and investigation of a three-dimensionally twisted diffuser for centrifugal compressors. ASME Paper No. 82-GT-102.

Morris, R. E., and Kenny, R. E. 1971. High-pressure ratio centrifugal compressors for small gas turbine engines. ASME Advanced Centrifugal Compressors :118-146.

Nakagawa, K., Keimi, Y., and Nishioka, T. 1995. Improved flow range in a radial compressor with vaned diffuser. (Proceedings of Fluid Machinery 1995 ASME FED Vol. 222), 133-140.

Nakagawa, K., and Uraki, Y. 1998. Comparison of two methods of flow range improvement in a centrifugal compressor. Proceedings of the 4th KSME-JSME Fluid Engineering Conference 109-112. Haeundae, Pusan, Korea, October 18-21.

Senoo, Y., Hayami, H., and Ueki, H. 1983. Low-solidity cascade diffuser for wide flow range centrifugal blowers. ASME Paper No. 83GT-3.

Yoshinaga, Y., Gyobu, I., Mishina, H., Koseki, F., and Nishida, H. 1980. Aerodynamic performance of a centrifugal compressor with vaned diffusers. ASME Journal of Fluid Engineering 102:486493. 

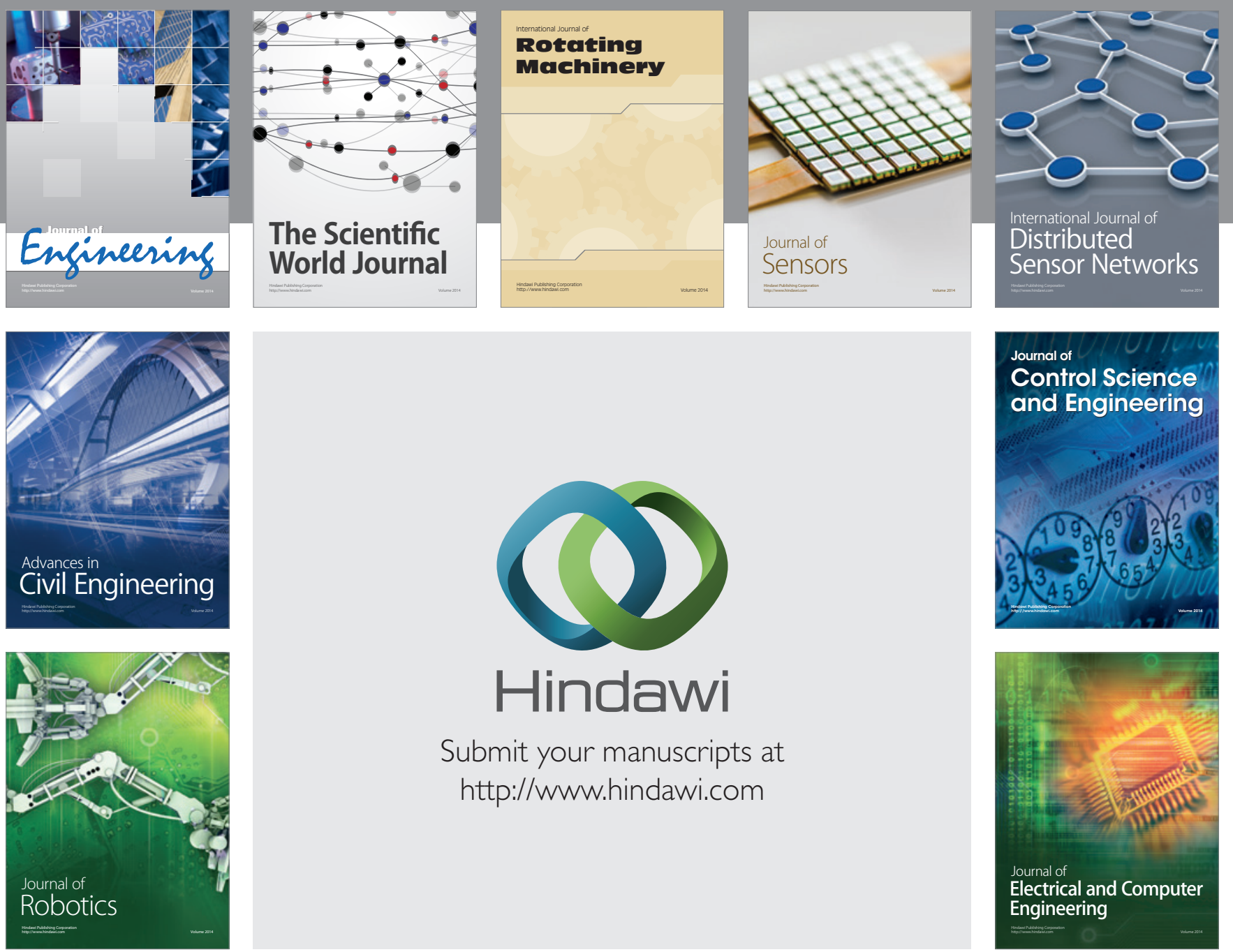

Submit your manuscripts at

http://www.hindawi.com
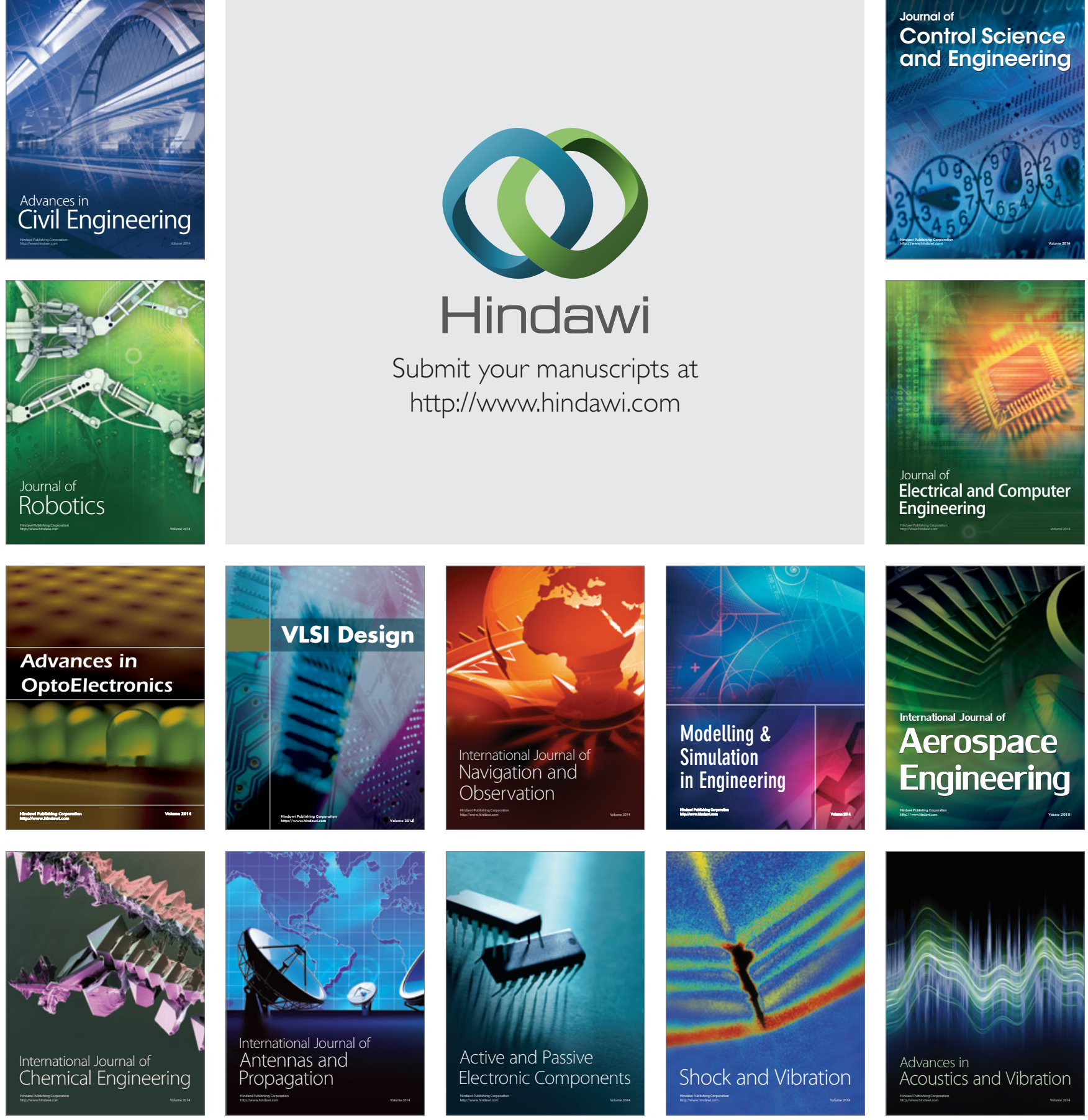